\section{Kidney expert to head holistic-medicine centre}

A specialist in kidney disease with a keen interest in non-traditional therapies has been named as the new head of the National Center for Complementary and Alternative Medicine in Bethesda, Maryland.

Josephine Briggs says she grew interested in alternative therapies while overseeing grants at the National Institute of Diabetes and Digestive and Kidney Diseases, where she launched studies on whether cranberry juice helps prevent urinary-tract infections and on the effects of saw palmetto in men with enlarged prostate glands.

Briggs says she isn't worried about disrespect from more traditional researchers. "Some of my friends roll their eyes, but I can deal with that," she says. "It's very important that this work be done and be done well."

\section{Early-warning system underestimates quake}

In October, Japan launched its nationwide system to warn people about strong earthquakes before they hit. But the system underestimated the strength of last week's quake near the nation's west coast.

The system is supposed to issue a warning, seconds before the shaking arrives, through television or loudspeakers to people in areas where the shaking will be a 'lower 5' or more on the Japanese system of seismic intensity. The scale, which ranges up to 7 , measures the level of shaking in any individual region, rather than at the epicentre of the quake. A lower 5 can break windows, put cracks in older buildings and knock over bookshelves.

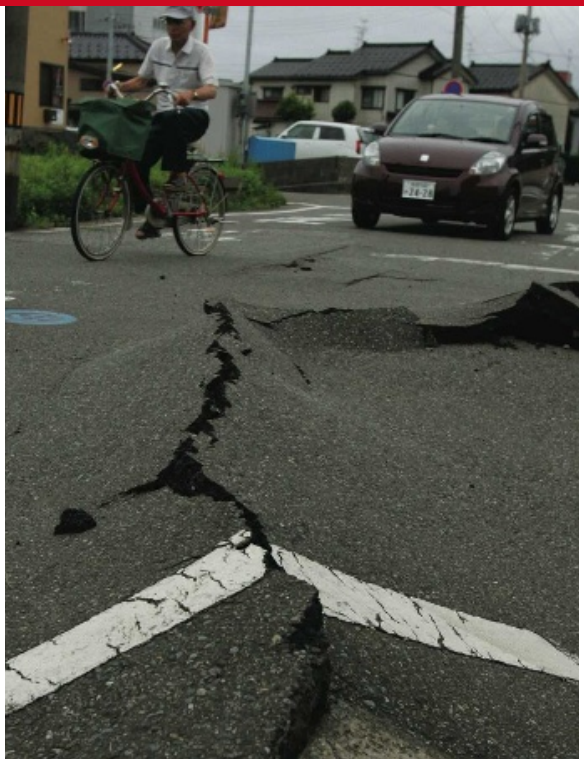

Are there cracks in Japan's quake warning system?

For last week's quake, the early-warning system predicted a shaking of intensity level 4, but some coastal cities experienced shaking in the range of a lower 5 . Takahito Nishimiya, a senior scientific officer in the seismology division at the Japan Meteorological Agency, says that such variation is within expected limits.

\section{Synthetic genome paves the way to artificial life}

The genome of the pathogenic bacterium Mycoplasma genitalium has been stitched together from scratch, creating a full set of instructions to make a living thing in the lab.

Hamilton Smith and his colleagues at the J. Craig Venter Institute in Rockville, Maryland, put together the 582,970 nucleotide bases - the building blocks of DNA - that constitute the M. genitalium

\title{
Gates foundation gives cash for agriculture in Africa
}

\section{Agriculture in developing} countries got a big boost last week, when the Seattlebased Bill \& Melinda Gates Foundation announced it would spend US $\$ 306$ million on projects aimed at improving agricultural productivity.

The bulk of the money $\$ 164.5$ million - will go to the Alliance for a Green Revolution in Africa, in Nairobi, Kenya, which will use it to fund projects to rejuvenate nutrient-depleted soils over 6.3 million hectares of African farmland.

The rest will be split between outfits that develop micro-irrigation technologies for smallholders in India, boost high-quality coffee production and milk quality in Kenya and elsewhere, and improve dairy farmers' access to markets in Bangladesh. The International Rice Research Institute in Manila, the Philippines, will receive $\$ 19.8$ million over three years, the largest single injection of money into rice research for several decades. genome. The genome is more than a factor of ten longer than the previous longest stretch of genetic material created by chemical means.

Next the team aims to find out whether cells can be 'booted up' into action when loaded with the genetic program.

\section{France and India to expand scientific collaborations}

Nuclear scientists in India and France will be working more closely together after several agreements were signed on 25 January during French President Nicolas Sarkozy's visit to New Delhi.

Indian researchers will participate in the construction of the Jules Horowitz research reactor, being built in Cadarache, France. They will also work with scientists at the GANIL heavy-ion accelerator in Caen.

Under another agreement, a neuroscience laboratory will be set up in India by India's National Brain Research Centre, the University of Paris and French medical research centre INSERM.

Delhi University and Grenoble University will set up two new joint master's programmes, in nanosciences and nuclear engineering. And additionally, India's Council of Scientific and Industrial Research and its French counterpart the CNRS will partner in green-chemistry approaches to find therapeutic agents for cancer and neurological disorders.

\section{OncoMed scores drug deal for $\$ 1.4$ billion with Glaxo}

The UK pharmaceutical giant GlaxoSmithKline has secured a US\$1.4-billion, five-year deal with the biotechnology company OncoMed Pharmaceuticals in Redwood City, California, to develop therapies based on cancer stem cells.

The deal, among the most lucrative ever for any preclinical company, has a certain risk because the cancer stem-cell theory is not universally accepted. The theory holds that tumours develop from specific stem cells that fail to be eliminated by chemotherapy and radiotherapy and thus reseed the cancer even after a long remission.

OncoMed has developed monoclonal antibodies to target and destroy such cancer stem cells. GlaxoSmithKline has secured the rights to four of them, which will now enter clinical trials.

\section{Correction}

In the News story 'Huge crystal baffles chemists' (Nature 451, 383; 2008), we mistakenly referred to the 'baubles' as the largest single-molecule crystals; in fact they are the largest crystallized single-molecule metal clusters. 